\title{
Fault Diagnosis of Transmission Lines with Rogowski Coils as Current Sensors
}

\author{
G. Sudha \\ Associate Professor \\ Department of Electrical \& \\ Electronic Engineering, \\ Bangalore Institute of \\ Technology
}

\author{
K.R.Valluvan, $\mathrm{PhD}$ \\ Professor \& Head \\ Department of Electrical \& \\ Electronic Engineering, Velalar \\ college of engineering \& \\ Technology, Erode, TN
}

\author{
T. Basavaraju, $\mathrm{PhD}$ \\ Director (Academics) \\ GSSIT, Bangalore
}

\begin{abstract}
This paper presents implementation of algorithms developed for fault classification and location detection on transmission lines with data from current $\&$ voltage sensors. Rogowski coil as current sensor is gaining importance due to its linearity and wide band width. A lumped parameter model of Rogowski coil is developed and integrated with a power system model in SIMULINK to simulate all types of faults at different locations, fault inception angles and fault resistances. A fault classification scheme based on the evaluation of angles of fault currents and voltages is extended to secondary values obtained from Rogowski coil. Further after estimation of phasors, fault location is detected. The test results show that the proposed algorithm on primary values is equally applicable on secondary values thus offering a fast and reliable technique for fault diagnosis of transmission lines in power systems.
\end{abstract}

\section{General Terms}

Fuzzy logic Fault Classifier (FFC), Fault distance

\section{Keywords}

Rogowski coil, lumped parameter model, symmetrical components, toroid, fault inception angle

\section{INTRODUCTION}

Transmission lines are vital to power systems as they constitute the back bone of power systems. Fault rate is usually much higher in transmission lines as compared to other components. Therefore, effective protection techniques for transmission line are essential. Due to increased complexity in power systems, need for faster fault clearing times, and difficulty in grading time/ over current relays, high speed digital distance relay is a good choice for transmission line protection. Transmission line fault location detection and classification has been a primary concern for high speed protective relaying and single pole auto-reclosures. Fault diagnosis is performed by computation of line impedance through the measurement of voltages and currents on one single end with respect to fault.

Traditional relaying equipment are provided with signals from iron cored voltage and current transformers (CT) having nonlinear magnetizing reactance. CT primary currents [1] can change from load currents to high fault currents. To avoid saturation, CTs are designed to operate at load currents on the lower portion of the magnetizing branch of V-I curve's linear region. It is desirable that CTs operate on the linear region without exceeding the saturation voltage even for fault currents. However, since short circuit currents may have a significant DC offset, it may saturate CTs [2] that would not saturate under symmetrical fault conditions.

Rogowski coils (RC) [3][4] are linear and provide advanced solutions for applications in multifunctional protective relaying. These schemes require fewer relays and current sensors than conventional designs, response times to faults are faster and adjustments to load and/or power system configuration changes can be easily made. Since RCs are very accurate and do not saturate, protection levels can be set to lower thresholds increasing the sensitivity of the scheme without affecting reliability of operation. This reduces the stress on protected equipment during faults. The system is immune to external magnetic fields. It is simple, user friendly, requires less wiring and space and can provide metering class accuracy.

MATLAB [5] has powerful high level programming features and tool box for system designing applications. Therefore the protection algorithms can be quickly implemented. Also the fuzzy tool box is used to design a fault classifier [6] based on the symmetrical components [7] of the fault current. SIMULINK [8] provides excellent GUI and block set, that allows flexible and rapid simulation of system models. Communication between MATLAB, SIMULINK and other tool boxes is very simple and doesn't require any change in formatting of the information to be exchanged. The above mentioned excellent advantages make MATLAB/SIMULINK a simple, convenient and interactive tool for simulation and testing of relay algorithm for various fault conditions

In [9], the author presents determination of phase angles of currents for fault classification through fuzzy logic technique. This paper presents a modification on fault classification presented in [10], to classify accurately all the 10 types of faults. Also, it proves the validity of the algorithm developed for fault diagnosis with primary values equally to the secondary values from Rogowski coil sensors.

\section{POWER SYSTEM AND ROGOWSKI COIL SIMULATION}

\subsection{Power System Simulation Parameters}

A $345 \mathrm{kV}$ power system as shown in Fig. 1 is modeled in SIMULINK to generate fault signals for various faults, fault distances and fault inception angles. The power system details are listed in appendix (1) where $S$ \& $R$ represents sending end and receiving end generators and $\mathrm{F}$, the location of fault at a distance ' $x$ ' from the sending terminal of a transmission line. The signals so obtained are processed to implement the logic for fault classification. 
A

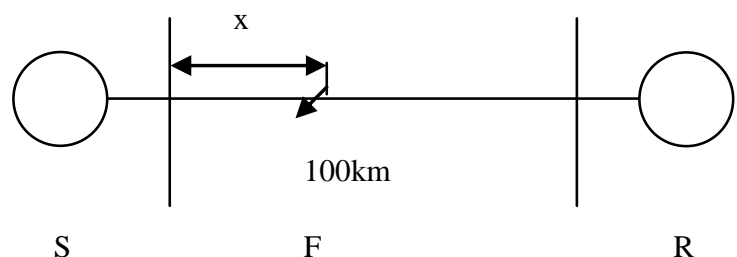

Fig 1: Simulated transmission system

\subsection{Rogowski coil Parameters}

Rogowski coil (RC) consists of wire wound on a nonmagnetic core. The coil is placed around the conductor whose current has to be measured. The construction of RC is shown in Fig. 2 and the geometric characteristics of the circular cross section Rogowski coil [11] [12] are given in Table 1.

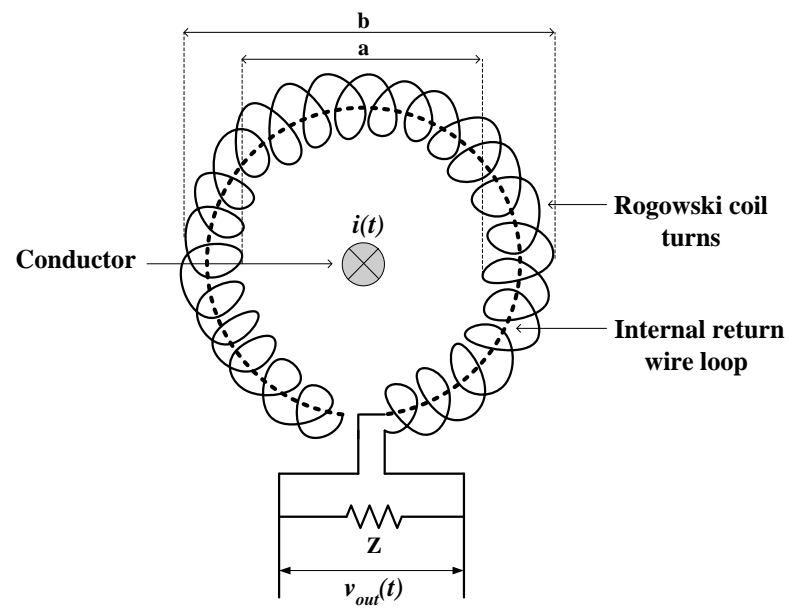

Signal to the measuring instrument

Fig 2: Construction of Rogowski coil

Table 1 Geometric characteristics of RC

\begin{tabular}{|c|c|}
\hline Rogowski Coil Dimensions & Specifications \\
\hline Inner diameter $a$ & $162.4 \mathrm{~mm}$ \\
\hline Outer diameter $b$ & $191 \mathrm{~mm}$ \\
\hline Transducer diameter $d_{r c}$ & $14.3 \mathrm{~mm}$ \\
\hline Length of the wire $l_{w}$ & $25 \mathrm{~m}$ \\
\hline Radius of the wire $d$ & $1 \mathrm{~mm}$ \\
\hline Length of the coil $l$ & $600 \mathrm{~mm}$ \\
\hline
\end{tabular}

\subsection{Rogowski coil Characteristics}

The most important characteristics of a Rogowski coil current sensor are:

- Large bandwidth allowing the measurement of current with fast transients as in power distribution and power electronic circuits.

- Large span because with the same coil it is possible to measure few amperes to kilo-amperes

- Good linearity, as the coil is air cored (nonmagnetic).

- No saturation, so the coil is not damaged by extra current.

- Galvanic isolation between the primary circuit and measuring circuit.

- The magnetic coupling between the primary and measuring circuit is in nano-henry, hence no charge effect.

Small size, lighter weight, high reliability, low losses and low cost are some more attractive features of Rogowski coils making them the best choice for protection of modern, complex power systems.

\subsection{Rogowski coil Simulation}

For a toroid coil having circular cross-section, the lumped parameters can be calculated using equations (1), (2) \& (3)

$$
\begin{aligned}
& R_{l}=\rho_{c} \frac{l_{w}}{\pi d^{2}} \\
& L_{l}=\frac{\mu_{0} N^{2} d_{r c}}{2 \pi} \log \frac{b}{a} \\
& C_{l}=\frac{4 \pi^{2} \varepsilon_{0}(b+a)}{\log \left[\frac{b+a}{b-a}\right]}
\end{aligned}
$$

Where $R_{l}, L_{l}$, and $C_{l}$ are the lumped resistance, inductance, and capacitance of the coil respectively. $\rho_{\mathrm{c}}$ is the copper resistivity; $\mu_{0}$ and $\varepsilon_{0}$ are the air permeability and permittivity, respectively; and $N=431$, is the number of turns of the coil [11]. The terminating impedance of the Rogowski coil $Z$ can be approximately calculated as given in reference [11]. The equivalent circuit of the Rogowski coil, based on the lumped parameters, is drawn in Fig. 3, where $i$ is the current flowing in the transmission line, $v_{r c}(t)$ is the induced voltage in the coil, $v_{\text {out }}(t)$ is the coil output voltage, and $M$ is the mutual inductance of the coil $(200 \mathrm{nH})$. 


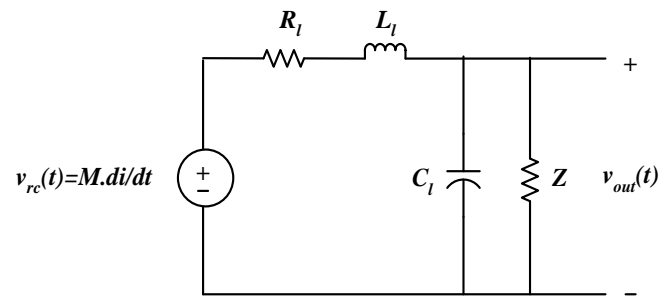

Fig 3: Equivalent lumped circuit of Rogowski coil

Table 2 Measured lumped values of RC

\begin{tabular}{|l|l|}
\hline Lumped model parameters & Measured Values \\
\hline Resistance $R_{l}$ & $0.11 \Omega$ \\
\hline Inductance $L_{l}$ & $0.6 \mu \mathrm{H}$ \\
\hline Capacitance $C_{l}$ & $50.3 \mathrm{pF}$ \\
\hline Terminating Impedance $Z$ & $2 \mathrm{~K} \Omega$ \\
\hline
\end{tabular}

The transfer function (Vout/Vrc) of the Rogowski coil lumped parameters model can be calculated as:

$$
\frac{V_{\text {out }}}{V_{r c}}=\frac{Z}{s^{2} L_{l} Z C_{l}+s\left(L_{l}+R_{l} Z C_{l}\right)+\left(R_{l}+Z\right)}
$$

The Rogowski coil output voltage is proportional to the rate of change of primary current. To obtain secondary current, the coil output voltage must be integrated.

\subsection{Fault Current Waveforms with \& without Rogowski coil}

On simulation of the Rogowski coil in SIMULINK the secondary signal along with the primary current for asymmetric line to ground fault (AG) is shown in Fig. 4. The integrated secondary signal is identical to primary waveform due to linear characteristics.

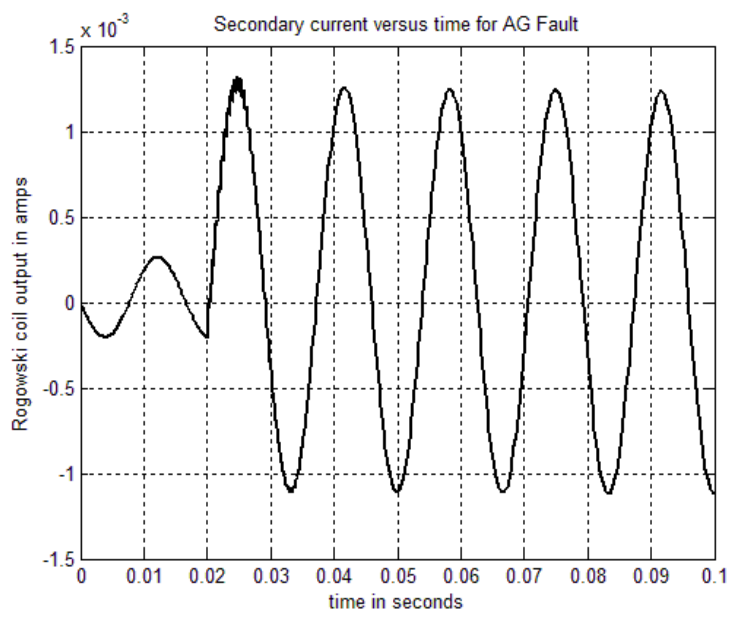

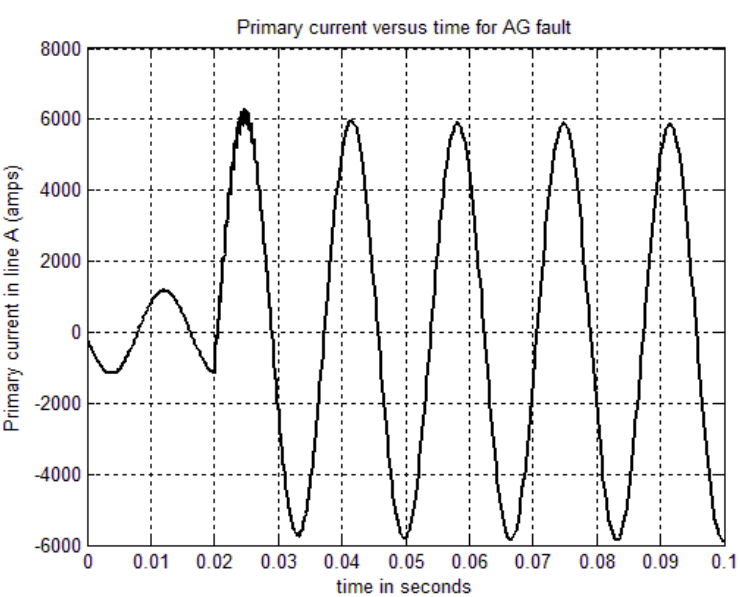

Fig 4: Secondary and primary currents versus time for AG fault.

\section{FUZZY LOGIC FAULT CLASSIFIER}

The need for accurate fault classification schemes to facilitate rapid fault location is of prime importance for effective and fast protection and system restoration operations. Most of the algorithms used in the past are based on the following techniques:

- Under-impedance

- $\quad$ Torque

- Over-current

A new technique based on the symmetrical components of fault currents is proposed [7] and verified to be $95 \%$ better than other fault location packages. The data required is only the three phase fault currents at the substation. The above technique can be implemented using fuzzy logic, neural network or expert system. Due to simplicity fuzzy logic approach [6] is preferred. The new algorithm is based on the angular differences among the sequence components of the fundamental fault current as well as on their relative magnitudes. Based on the three phase fault currents $\left(\mathrm{I}_{\mathrm{A}}, \mathrm{I}_{\mathrm{B}}, \mathrm{I}_{\mathrm{C}}\right)$ the zero, positive and negative sequential components with respect to phase a $\left[I_{a 0}, I_{a 1}, I_{a 2}\right]$, phase $\mathrm{b}\left[I_{b 0}, I_{b 1}, I_{b 2}\right]$ and phase $\mathrm{c}\left[I_{c 0}, I_{c 1}, I_{c 2}\right]$, the phase angle difference between the positive and negative sequence components and the normalized zero sequence and negative sequence currents are evaluated using (5), (6) \& (7)

$\left[\begin{array}{l}I_{a 0} \\ I_{a 1} \\ I_{a 2}\end{array}\right]=\frac{1}{3}\left[\begin{array}{ccc}1 & 1 & 1 \\ 1 & a & a^{2} \\ 1 & a^{2} & a\end{array}\right]\left[\begin{array}{c}I_{a} \\ I_{b} \\ I_{c}\end{array}\right]$

$\left[\begin{array}{l}I_{b 0} \\ I_{b 1} \\ I_{b 2}\end{array}\right]=\frac{1}{3}\left[\begin{array}{ccc}1 & 1 & 1 \\ 1 & a & a^{2} \\ 1 & a^{2} & a\end{array}\right]\left[\begin{array}{c}I_{b} \\ I_{c} \\ I_{a}\end{array}\right]$

$\left[\begin{array}{l}I_{c 0} \\ I_{c 1} \\ I_{c 2}\end{array}\right]=\frac{1}{3}\left[\begin{array}{ccc}1 & 1 & 1 \\ 1 & a & a^{2} \\ 1 & a^{2} & a\end{array}\right]\left[\begin{array}{c}I_{c} \\ I_{a} \\ I_{b}\end{array}\right]$

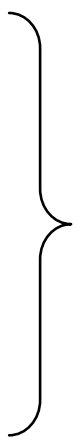

$\operatorname{ang} \_\mathrm{A}=\operatorname{abs}\left(\operatorname{angle}\left(\mathrm{I}_{\mathrm{a} 1}\right)-\right.$ angle $\left.\left(\mathrm{I}_{\mathrm{a} 2}\right)\right)$

ang_B $=\operatorname{abs}\left(\operatorname{angle}\left(\mathrm{I}_{\mathrm{b} 1}\right)-\right.$ angle $\left.\left(\mathrm{I}_{\mathrm{b} 2}\right)\right)$

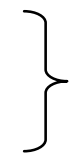


ang_C $=$ abs $\left(\operatorname{angle}\left(\mathrm{I}_{\mathrm{c} 1}\right)-\operatorname{angle}\left(\mathrm{I}_{\mathrm{c} 2}\right)\right)$

$\mathrm{R}_{\mathrm{of}}=\operatorname{abs}\left(\mathrm{I}_{\mathrm{a} 0} / \mathrm{I}_{\mathrm{a} 1}\right)$

$\mathrm{R}_{2 \mathrm{f}}=\mathrm{abs}\left(\mathrm{I}_{\mathrm{a} 2} / \mathrm{I}_{\mathrm{a} 1}\right)$

The fundamental relation between angles and current ratios for all asymmetrical faults (AG, BG, CG, AB, BC, CA, ABG, $\mathrm{BCG}$, and $\mathrm{CAG}$ ) is given in Table 3 . For symmetrical fault the zero and negative sequence components do not exist in the system, hence the angles ang_A, ang_B and ang_C are not defined. The values of $K$ and $K_{1}$ are defined by equations (8), where $Z_{2}, Z_{0} \& Z_{f}$ are the negative sequence impedance, zero sequence impedance of the line and fault impedance respectively.

The values specified in Table 3 are valid only if the resistance in the fault path is negligibly small.

$K=Z_{2} /\left(Z_{2}+Z_{0}+3 Z_{f}\right)$

$K_{1}=\left(Z_{2}+3 Z_{f}\right) /\left(Z_{2}+Z_{0}+3 Z_{f}\right)$

Table 3 Fundamental Relation for Asymmetrical Faults

\begin{tabular}{|c|c|c|c|c|c|}
\hline $\begin{array}{c}\text { Type of } \\
\text { fault }\end{array}$ & ang_A & ang_B & ang_C & $\mathbf{R}_{\text {of }}$ & $\mathbf{R}_{\mathbf{2 f}}$ \\
\hline AG & $0^{\circ}$ & $120^{\circ}$ & $120^{\circ}$ & 1.0 & 1.0 \\
\hline BG & $120^{\circ}$ & $0^{\circ}$ & $120^{\circ}$ & 1.0 & 1.0 \\
\hline CG & $120^{\circ}$ & $120^{\circ}$ & $0^{\circ}$ & 1.0 & 1.0 \\
\hline AB & $60^{\circ}$ & $60^{\circ}$ & $180^{\circ}$ & 0.0 & 1.0 \\
\hline BC & $180^{\circ}$ & $60^{\circ}$ & $60^{\circ}$ & 0.0 & 1.0 \\
\hline CA & $60^{\circ}$ & $180^{\circ}$ & $60^{\circ}$ & 0.0 & 1.0 \\
\hline ABG & $60^{\circ}$ & $60^{\circ}$ & $180^{\circ}$ & $\mathrm{K}$ & $\mathrm{K}_{1}$ \\
\hline BCG & $180^{\circ}$ & $60^{\circ}$ & $60^{\circ}$ & $\mathrm{K}$ & $\mathrm{K}_{1}$ \\
\hline $\mathrm{CAG}$ & $60^{\circ}$ & $180^{\circ}$ & $60^{\circ}$ & $\mathrm{K}$ & $\mathrm{K}_{1}$ \\
\hline SYM & - & - & - & 0.0 & 0.0 \\
\hline
\end{tabular}

\subsection{Design of FFC}

The properties of the fuzzy logic based fault classifier (FFC) as obtained from Fuzzy Inference System toolbox in MATLAB is given in Table 4. It has five inputs ang_A, ang_B, ang_C, Rof, R2f and an output fault_type (FT), each of the three input variables ang_A, ang_B and ang_C are defined by four fuzzy variables: AZ, AS, AO, AOE (approximately zero, approximately $60^{\circ}$, approximately $120^{\circ}$, approximately $180^{\circ}$ ) and the other two Rof and R2f are defined by two fuzzy variables: low_Rof, high_Rof, low_R2f, high_R2f. All the fuzzy variables and their ranges are defined in Table 5. It is to be noted that these relationships are valid for faults in an unloaded system.

Table 4 Properties of fuzzy fault classifier

\begin{tabular}{|l|l|}
\hline Name & Fault_class1 \\
\hline Type & mamdani \\
\hline NumInputs & 5 \\
\hline InLabels & ang_A, ang_B, ang_C, Rof, R2f \\
\hline
\end{tabular}

\begin{tabular}{|l|l|}
\hline NumOutputs & 1 \\
\hline OutLabels & FT \\
\hline NumRules & 10 \\
\hline AndMethod & $\min$ \\
\hline OrMethod & $\max$ \\
\hline ImpMethod & $\min$ \\
\hline AggMethod & max \\
\hline DefuzzMethod & centroid \\
\hline
\end{tabular}

Table 5 Fuzzy Variables with their ranges

\begin{tabular}{|c|c|c|c|}
\hline \multirow{2}{*}{ Fuzzy variable } & \multicolumn{3}{|c|}{ Triplets } \\
\cline { 2 - 4 } & $\mathrm{A}$ & $\mathrm{B}$ & $\mathrm{C}$ \\
\hline approximately $0^{\circ}$ (AZ) & $0^{\circ}$ & $0^{\circ}$ & $35^{\circ}$ \\
\hline $\begin{array}{c}\text { approximately } 60^{\circ} \\
\text { (AS) }\end{array}$ & $35^{\circ}$ & $60^{\circ}$ & $95^{\circ}$ \\
\hline $\begin{array}{c}\text { approximately } 120^{\circ} \\
\text { (AO) }\end{array}$ & $85^{\circ}$ & $120^{\circ}$ & $155^{\circ}$ \\
\hline $\begin{array}{c}\text { approximately } 180^{\circ} \\
(\text { AOE) }\end{array}$ & $145^{\circ}$ & $180^{\circ}$ & $215^{\circ}$ \\
\hline $\begin{array}{c}\text { Low- } \mathrm{R}_{\text {of }} \text { (low) } \\
\text { high- } \mathrm{R}_{\text {of }}(\text { high) }\end{array}$ & 0 & 0 & 0.26 \\
\hline Low- $_{2 \mathrm{f}}$ (low) & 0 & 0 & 0.45 \\
\hline high- $\mathrm{R}_{\text {of }}$ (high) & 0.45 & 0.975 & 1.8 \\
\hline
\end{tabular}

A partial rule base for different fault categories is described below:

1. If ang_A is $\mathrm{AZ}$ and ang_B is $\mathrm{AO}$ and ang_C is $\mathrm{AO}$ and Rof is high and R2 $\mathrm{f}$ is high

Then fault_type is AG

2. If ang_A is AS and ang_B is AS and ang_C is AOE and Rof is low and $\mathrm{R} 2 \mathrm{f}$ is high

Then fault_type is $\mathrm{AB}$

3. If ang_A is AS and ang_B is AS and ang_C is AOE and Rof is high and $\mathrm{R} 2 \mathrm{f}$ is high

Then fault_type is ABG

4. If Rof is low and R2f is low

Then fault_type is SYM

\subsection{Input and Output of FFC with and without Rogowski coil}

The typical output of fault classifier with primary and secondary values is listed in Table 6 \& Table 7, depending on the pre-fault power level, fault resistance, fault location, fault inception angle(FIA) etc., the values of these five quantities deviate from their corresponding ideal values as in Table 5. The output tabulated is for a fault distance of $50 \mathrm{~km}$ with 
respect to $S$, fault resistance of $1 \Omega$ and fault inception angle (FIA) of $0^{\circ}$.

Table 6 Input \& Output of FFC with primary values

\begin{tabular}{|l|l|l|l|l|l|l|}
\hline Fault & ang_A & ang_B & ang_C & Rof & R2f & o/p \\
\hline AG & 30.93 & 89.06 & 150.93 & 0.8981 & 0.9316 & 0.2 \\
\hline BG & 152.69 & 32.69 & 87.3 & 0.8889 & 0.9231 & 1 \\
\hline CG & 87.0 & 153.01 & 33.0 & 0.8625 & 0.8941 & 2 \\
\hline AB & 74.3 & 45.69 & 165.69 & $4.8 \mathrm{e}-6$ & 0.9787 & 3 \\
\hline BC & 165.39 & 74.611 & 45.39 & $4.9 \mathrm{e}-6$ & 0.9821 & 4 \\
\hline CA & 45.4 & 165.4 & 74.59 & $4.9 \mathrm{e}-6$ & 0.9821 & 5 \\
\hline ABG & 65.2 & 54.79 & 174.8 & 0.283 & 0.6943 & 6 \\
\hline BCG & 168.9 & 71.11 & 48.89 & 0.2697 & 0.7096 & 7 \\
\hline CAG & 50.62 & 170.62 & 69.377 & 0.2674 & 0.766 & 8 \\
\hline SYM & - & - & - & $7.9 \mathrm{e}-$ & 0.0852 & 9 \\
& & & & 12 & & \\
\hline
\end{tabular}

Table 7 Input \& Output of FFC with secondary values

\begin{tabular}{|l|l|l|l|l|l|l|}
\hline Fault & ang_A & ang_B & ang_C & Rof & R2f & o/p \\
\hline AG & 32.65 & 87.34 & 152.65 & 0.8922 & 0.9112 & 0.1 \\
\hline BG & 152.65 & 32.65 & 87.34 & 0.9128 & 0.9081 & 1 \\
\hline CG & 86.52 & 153.49 & 33.48 & 0.9496 & 0.9234 & 2 \\
\hline AB & 74.78 & 45.21 & 165.21 & $5.6 \mathrm{e}-6$ & 0.9721 & 3 \\
\hline BC & 165.68 & 74.33 & 45.67 & $7.1 \mathrm{e}-6$ & 0.9733 & 4 \\
\hline CA & 45.41 & 165.41 & 74.58 & $3.5 \mathrm{e}-6$ & 0.9689 & 5 \\
\hline ABG & 69.62 & 50.3 & 170.37 & 0.2732 & 0.7196 & 6 \\
\hline BCG & 169.4 & 70.62 & 49.38 & 0.2673 & 0.7134 & 7 \\
\hline CAG & 49.44 & 169.44 & 70.55 & 0.2768 & 0.73 & 8 \\
\hline SYM & - & - & - & $\begin{array}{l}3.7 e- \\
11\end{array}$ & 0.0129 & 9 \\
& & & & & \\
\hline
\end{tabular}

\section{FAULT LOCATION IDENTIFIER}

\subsection{Fault impedance $\&$ distance Calculation}

On estimation of current and voltage phasors by applying Fourier transformation as well as the zero sequence current component $\mathrm{I}_{0}$, the fault impedance for various faults is determined [13] using formulae shown in Table 8.

Table 8 Fault impedance calculation formula on different faults

\begin{tabular}{|l|l|}
\hline Fault Type & Formula \\
\hline AG & $\mathrm{V}_{\mathrm{A}} /\left(\mathrm{I}_{\mathrm{A}}+\mathrm{kI}_{0}\right)$ \\
\hline BG & $\mathrm{V}_{\mathrm{B}} /\left(\mathrm{I}_{\mathrm{B}}+\mathrm{kI}_{0}\right)$ \\
\hline CG & $\mathrm{V}_{\mathrm{C}} /\left(\mathrm{I}_{\mathrm{C}}+\mathrm{kI}_{0}\right)$ \\
\hline
\end{tabular}

\begin{tabular}{|l|l|}
\hline AB or $A B G$ & $\left(\mathrm{~V}_{\mathrm{A}^{-}}-\mathrm{V}_{\mathrm{B}}\right) /\left(\mathrm{I}_{\mathrm{A}}-\mathrm{I}_{\mathrm{B}}\right)$ \\
\hline $\mathrm{BC}$ or $\mathrm{BCG}$ & $\left(\mathrm{V}_{\mathrm{B}}-\mathrm{V}_{\mathrm{C}}\right) /\left(\mathrm{I}_{\mathrm{B}}-\mathrm{I}_{\mathrm{C}}\right)$ \\
\hline CA or CAG & $\left(\mathrm{V}_{\mathrm{C}}-\mathrm{V}_{\mathrm{A}}\right) /\left(\mathrm{I}_{\mathrm{C}}-\mathrm{I}_{\mathrm{A}}\right)$ \\
\hline
\end{tabular}

Where $\mathrm{A}, \mathrm{B}$ and $\mathrm{C}$ indicates three phases, $\mathrm{G}$ is ground, $\mathrm{V}$ and $\mathrm{I}$ are phasors of voltage and current, $\mathrm{k}=\left(\mathrm{Z}_{0}-\mathrm{Z}_{1}\right) / \mathrm{Z}_{1}, \mathrm{Z}_{0}$ and $\mathrm{Z}_{1}$ are zero-sequence, positive-sequence impedances of line respectively. $\mathrm{I}_{0}$ is zero-sequence current.

Since the impedance of the total line length is a known quantity, the fault distance can be obtained as it is proportional to the evaluated fault impedance according to expression (9),

$L_{f}=Z_{f} / Z_{L} \times L$

Where $Z_{f}$ represents fault impedance, $Z_{L}$ the total line impedance and $\mathrm{L}$ the total line length.

\subsection{Error With \& Without RC}

The $\%$ error between actual distance (Actual dist) and measured distance (Measured dist) is calculated as,

$\%$ Error $=\frac{(\text { Actual dist }- \text { Measureddist })}{\text { Actualdist }} \times 100$

The distance at which fault is simulated is termed as actual fault distance. For various fault distances the power system simulation is executed to obtain the primary fault currents and voltages by applying Discrete Fourier transformation and hence the fault impedance and fault distance are computed using Table 8 and equation 9 respectively. In the next case, Discrete Fourier transformation is applied on the fault currents and voltages obtained from Rogowski coil. There from, the fault impedance and fault distance are determined from Table 8 and equation (9). This is repeated for various faults like AG, $\mathrm{ABG}$ and $\mathrm{AB}$ faults. Also the \% error using equation (10) is computed and tabulated as shown in Tables $9,10 \& 11$. It shows that in worst cases the \%error ranges between -3.9 to 1.5 with primary values while with $\mathrm{RC}$ it ranges between -0.8 to 2.3 indicating that the fault distance obtained from $\mathrm{RC}$ is more accurate hence justifying the usage of Rogowski coils as current sensors instead of current transformers. Tables 9, $10 \& 11$ are only sample outputs, while the system has been tested for all the types of faults with different FIA and fault resistance.

Table 9 Fault distances and error for AG fault

\begin{tabular}{|l|l|l|l|l|}
\hline \multicolumn{5}{|c|}{ AG FAULT } \\
\hline $\begin{array}{l}\text { Actual } \\
\text { fault } \\
\text { distance } \\
(\mathrm{km})\end{array}$ & $\begin{array}{l}\text { distance } \\
\text { with pri } \\
\text { values } \\
(\mathrm{km})\end{array}$ & $\begin{array}{l}\text { \% Error } \\
\text { with } \\
\text { primary } \\
\text { values }\end{array}$ & $\begin{array}{l}\text { distance } \\
\text { with } \\
\text { RC(km) }\end{array}$ & $\begin{array}{l}\text { Error } \\
\text { with } \\
\text { RC }\end{array}$ \\
\hline 20 & 19.82 & 0.9 & 20.05 & \\
& & & -0.25 \\
\hline
\end{tabular}




\begin{tabular}{|l|l|l|l|l|}
\hline 40 & 40.26 & -0.65 & 39.84 & 0.4 \\
\hline 60 & 61.42 & -2.36 & 59.80 & 0.333 \\
\hline 80 & 79.16 & 1.05 & 79.62 & 0.475 \\
\hline
\end{tabular}

\section{Appendix 1:}

Transmission power system parameters

Voltage rating: $345 \mathrm{kv}$

System frequency: $60 \mathrm{~Hz}$

Equivalent Voltage per unit:

$E s=1\left\llcorner 15^{\circ}\right.$ (p.u.), $E r=1\left\llcorner 0^{\circ}\right.$ (p.u.)

Equivalent Source Impedance:

$\mathrm{Zs} 1=0.238+5.72(\Omega), \mathrm{Zs} 0=2.738+10(\Omega)$

$\mathrm{Zr} 1=0.238+6.19(\Omega), \mathrm{Zr} 0=0.833+5.12(\Omega)$

Length of Transmission Line: $100 \mathrm{~km}$

Line Constants:

$\mathrm{R} 0=0.275(\Omega), \mathrm{L} 0=3.725(\mathrm{mH}), \mathrm{C} 0=6.71(\mathrm{nF})$

$\mathrm{R} 1=0.0275(\Omega), \mathrm{L} 1=1.345(\mathrm{mH}), \mathrm{C} 1=9.483(\mathrm{nF})$

\section{REFERENCES}

[1] Lj. A. Kojovic, "CT Modelling Techniques for Relay Protection System Transient Studies", International Conference on Power Systems Transients - IPST 2003, New Orleans, September 2003.

[2] Lj. A. Kojovic, "Comparison of Different Current Transformer Modelling Techniques for Protection System Studies", IEEE/PES Summer Meeting, Chicago, Illinois, July 2002.

[3] Jan Hlavacek, Radek Prochazka, Karel Draxler, Vladislav Kvasnicka, "The Rogowski Coil Design Software department of Power Engineering", CTU FEE in Prague, Technicka 2, 16627 Prague 6, Czech Republic

[4] Practical Aspects of Rogowski Coil Applications to Relaying, Special Report, September 2010, Sponsored by the Power System Relaying Committee of the IEEE Power Engineering Society

[5] The Math works INC, "using MATLAB"

[6] G.Sudha, Dr.T.Basavaraju, "Simulation and Testing of a Digital Distance Relay with Fuzzy Logic Based Faulttype Identification using MATLAB/SIMULINK", at International Conference on Power System Protection, held at CPRI, Bangalore during 20-21 Feb 2007.

[7] Biswarup Das, "Fuzzy logic based fault-type Identification in balanced radial power distribution System", IEEE Transaction on power delivery, vol.21, No.1, January 2006

[8] The Math works INC, "SIMULINK"

[9] The Rogowski coil and the voltage divider in power system protection and monitoring, Pentti Mähönen, Vesa Virtanen, ABB Transmit Oy, Tapio Hakola, ABB Substation Automation Oy, Vaasa, Finland

[10] Huisheng Wang and W W L Keerthipala, "Fuzzy-neuro approach to fault classification for transmission line protection", IEEE Transaction on power delivery, vol.13, No.4, October 1998

[11] G. Murtaza Hashmi Matti Lehtonen Abdelsalam Elhaffar," Modelling Of Rogowski Coil For On-Line Pd Monitoring In Covered conductor Overhead Distribution Networks" CIRED 19th International Conference On Electricity Distribution Vienna, 21-24 May 2007 Paper 0207 
[12] Lj. A. Kojovic, Senior member, IEEE," Rogowski Coil Transient Performance and ATP Simulations for Applications in Protective Relaying" ,Presented at the International Conference on Power Systems Transients (IPST'05) in Montreal, Canada on June 19-23, 2005 Paper No. IPST05 - 010

[13] Thompson Adu, Senior member, IEEE, “An Accurate Fault Classification Technique for Power System Monitoring Devices" IEEE Transactions on Power Delivery, vol. 17, no. 3, July 2002

[14]Artero J.A. E.R.Z. Endesa Distribución C/ San 1, 50001 Zaragoza, Arcega F.J, Department of Electrical Engineering, Zaragoza, "Influence of External Currents in Sensors Based on PCB Rogowski Coils

\section{AUTHORS' PROFILES}

G. SUDHA received her BE (Electrical) \& ME (Power systems) from Bangalore University in 1987 \& 1990 respectively. During 1987-88 she worked as lecturer at RV College of Engineering, Bangalore. From 1990 till date she is working at Bangalore Institute of Technology in various capacities as lecturer, Assistant Professor and Associate Professor. She is currently pursuing $\mathrm{PhD}$ at Anna University, Chennai. Her research interests include soft computing techniques in power system protection, power quality analysis, communication engineering in power system operation, control \& protection, IED and agent based schemes in protection.

DR.K.R.VALLUVAN received BSc (Physics) from Madras University in 1982, BTech (Electronics Engg.) from Madras
Institute of Technology, Anna University in 1985, PG Diploma in Electronics Design Technology from Indian Institute of Science in 1986, ME (Computer Science \& Engg.) from Bharathiar University in 2001. He was awarded $\mathrm{PhD}$ by Anna University in 2009 for the thesis titled "Implementation of ADALINE on DSP and FPGA for Measurement of Harmonics". He has worked as Quality Engineer in ABB, Hardware Development Manager in SPA Computers and Senior Design Engineer in Wipro GE Medical Systems. He was a Professor in Kongu Engineering College between 19972010 and EBET during 2010-11. He has completed more than 30 industrial consultancy projects in embedded systems, power quality studies and energy conservation. $\mathrm{He}$ is currently Professor in the Dept. of ECE, Velalar College of Engg. \& Technology, Erode. His areas of interest are embedded systems, neuro-fuzzy systems, power quality improvement and energy conservation

Dr. T.BASAVARAJU had his BE (Electrical) from university of Mysore in 1962 and M.Sc (Engg.) in Power system from University of Madras in 1967. He obtained PhD from Bangalore University in the year 1980. He served as lecturer in Electrical Engineering for 5years at Malnad College of Engineering, Hassan, Karnataka and at University Visvesvaraya College of Engineering of Bangalore University for 34 years, since 1968 in various capacities as lecturer, Reader and professor in the Department of Electrical Engineering. He also worked as Principal at Alpha College of engineering, Bangalore from 2002 - 04, Director (Academics) SRSIT, from 2005 - 2012 and currently, Director (Academics) at GSSIT Bangalore. His fields of interest are electrical network theory, EMF, electrical machines and power systems. 